\title{
Metabolomic insights into the browning of the peel of bagging 'Rui Xue' apple fruit
}

Hui Wang ${ }^{1}$, Shuang Wang ${ }^{1}$, Miao-Miao Fan ${ }^{1}$, Shu-Hui Zhang ${ }^{2}$, Lu-Long Sun ${ }^{1 *}$ and Zheng-Yang Zhao ${ }^{1 *}$

\begin{abstract}
Background: Bagging is one of the most important techniques for producting high-quality fruits. In the actual of cultivating, we found a new kind of browning in peel of apple fruit that occurs before harvest and worsen during storage period. There are many studies on metabonomic analysis of browning about storage fruits, but few studies on the mechanism of browning before harvest.

Results: In this study, five-year-old trees of 'Rui Xue' (CNA20151469.1) were used as materials. Bagging fruits without browning (BFW) and bagging fruits with browning (BFB) were set as the experimental groups, nonbagging fruits (NBF) were set as control. After partial least squares discriminant analysis (PLS-DA), 50 kinds of metabolites were important with predictive VIP $>1$ and $p$-value $<0.05$. The most important differential metabolites include flavonoids and lipids molecules, 11 flavonoids and 6 lipids molecules were significantly decreased in the BFW compared with NBF. After browning, 11 flavonoids and 7 lipids were further decreased in BFB compared with BFW. Meanwhile, the significantly enriched metabolic pathways include galactose metabolism, ABC membrane transporter protein, flavonoid biosynthesis and linoleic acid metabolism pathways et al. Physiological indicators show that, compared with NBF, the content of malondialdehyde (MDA), hydrogen peroxide $\left(\mathrm{H}_{2} \mathrm{O}_{2}\right)$, superoxide anion $\left(\mathrm{O}_{2}{ }^{-}\right)$in peel of BFW and BFB were significantly increased, and the difference of $\mathrm{BFB}$ was more significant. Meanwhile, the antioxidant enzyme activities of BFW and BFB were inhibited, which accelerated the destruction of cell structure. In addition, the metabolome and physiological data showed that the significantly decrease of flavonoid was positively correlated with peel browning. So, we analyzed the expression of flavonoid related genes and found that, compared with NBF, the flavonoid synthesis genes MdLAR and MdANR were significantly up-regulated in BFW and BFB, but, the downstream flavonoids-related polymeric genes MdLAC7 and MdLAC14 were also significantly expressed.
\end{abstract}

Conclusions: Our findings demonstrated that the microenvironment of fruit was changed by bagging, the destruction of cell structure, the decrease of flavonoids and the increase of triterpenoids were the main reasons for the browning of peel.

Keywords: Malus domestica Borkh., Fruit bagging, 'Rui Xue', Browning, Metabolomic

\footnotetext{
*Correspondence: Iulongsun@126.com; zhaozy@nwsuaf.edu.cn

${ }^{1}$ College of Horticulture, Northwest A \& F University, Yangling, Xianyang

712100, Shaanxi, China

Full list of author information is available at the end of the article
}

(c) The Author(s). 2021 Open Access This article is licensed under a Creative Commons Attribution 4.0 International License, which permits use, sharing, adaptation, distribution and reproduction in any medium or format, as long as you give appropriate credit to the original author(s) and the source, provide a link to the Creative Commons licence, and indicate if changes were made. The images or other third party material in this article are included in the article's Creative Commons licence, unless indicated otherwise in a credit line to the material. If material is not included in the article's Creative Commons licence and your intended use is not permitted by statutory regulation or exceeds the permitted use, you will need to obtain permission directly from the copyright holder. To view a copy of this licence, visit http://creativecommons.org/licenses/by/4.0/ The Creative Commons Public Domain Dedication waiver (http://creativecommons.org/publicdomain/zero/1.0/) applies to the data made available in this article, unless otherwise stated in a credit line to the data. 


\section{Background}

Apple is one of the most produced fruits in the world, which occupies an important position in the world fruit trade [1]. China has become the largest producer of apple in the world (Food and Agriculture Organization of the United Nations, FAO). In 2018, China's apple cultivation area has reached 2.072 million $\mathrm{hm}^{2}$, accounting for $57.7 \%$ of the world's total cultivation area, and the total production reached 39.235 million tons, accounting for $54.5 \%$ of the world's total apple production.

The fruit with bright color, smooth surface and no pesticide residue is favored by consumers at present. Fruit bagging as one of the most important good agricultural practice to produce high quality fruit $[2,3]$. It has been used in several fruit crops to improve the peel color and surface smoothness, and to reduce the incidence of disease, insect pests, sunburn of the peel, and bird damage [3-8]. It has been widely used in China, Australia, Japan, and the United States for the cultivation of peach, apple, pear, grape, loquat and so on [3, 9]. However, bagging can also induce some negative effects on fruits. The microenvironment after bagging will reduce the thickness of peel and the content of sugar, acid, mineral elements, and other internal soluble substances in fruits $[7,10]$. After bagging, the dark condition could inhibit the synthesis and accumulation of antioxidant substances, such as flavonoids and phenols in fruits [1113], thereby reduced the fruits' resistance to stress.

One interesting phenomenon was observed that browning in peel was easily occurred in bagging fruits, especially some late-ripening varieties, including 'Fuji', 'Golden Delicious', 'Pink Lady', 'Envy', 'Rui Xue', and so on, which occurred at the late stage of fruit growth (from September to October) in the field (Fig. 1). While no browning occurred in unbagging fruits. The new kind of browning is different from the superficial scald, which occurs before harvest and worsen during storage period, and flavonoids were significantly reduced and triterpenoids increased along with browning. While, superficial scald only occurs during storage, and $\alpha$-farnesene synthase (MdAFS1) of TPS enzymes and its oxidative product have been identified as key factors causing superficial scald [14]. Before harvest, browning started at stalk cavity and then expanded to the whole surface. Meanwhile, the stalk cavity and other expanded part changes from pale brown to brown and dark brown (Fig. 2). During storage, the healthy surface deteriorates gradually by outward diffusion from the stalk cavity. Seriously, the brown part could penetrate into the fruit interior, without any peculiar smell. Although the new kind of browning doesn't affect its taste, the appearance of fruit was influenced, which reduces its value $[15,16]$.

Previous studies on fruit browning mainly focused on storage period. Including long-term low temperaturestored induced the peel browning of pears, apples, mangoes, bananas and so on [17-19]. Luo discovered that the antioxidant and redox system are directly linked to apple soft scald development at low temperature by metabonomics techniques [19]. Jordi indicated the mechanism of ethylene mediated pear peel browning under low temperature was explained by metabonomic techniques [20]. Chen also used metabonomic techniques suggested that peel browning could induce the conversion of metabolic products from amino acids to terpenes [17]. Previous analyses have revealed changes in the metabolism of reactive oxygen species generated by the tricarboxylic acid cycle (TCA) and $\gamma$-aminobutyric acid (GABA) shunt, which causes stressed conditions inside the mesocarp. Further, reduced levels of antioxidants and enzymes dissipating reactive oxygen species in mesocarp deteriorate the fruit physiology. This oxidative stress all along aects the level of amino acids, sugars and enzymes responsible for flavor generation in the fruit [18, $19,21]$. However, how bagging induced browning has not been thoroughly studied. In addition, few studies have attempted to use comparative metabolomics to investigate the mechanism of peel browning before harvest.

We hypothesized that bagging changed the microenvironment of apple fruit, reducing the antioxidant capacity of peel, leading to a thinner peel, and in the regions with large differences in temperature between day and night, the antioxidant content in fruit is reduced, the structure of the cells is altered, and enzymatic browning of the fruit on the tree is induced after the cell membrane broken. Here, we conducted a metabolomic analysis to study the browning mechanism of apple peel

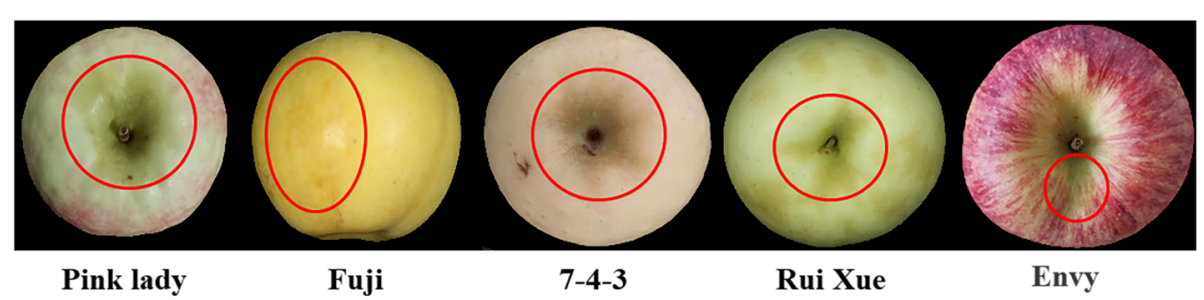

Fig. 1 Investigation on different late-ripening varieties about peel browning 


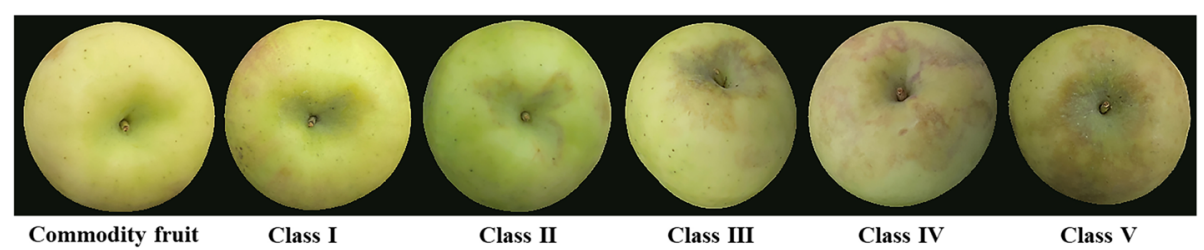

Fig. 2 The classification in apple peel browning about bagging 'Rui Xue'

using the sensitive variety 'Rui Xue'. The findings were helpful for our understanding in the physiological changes of peel before harvest, refining the cultivation techniques before harvest and storage techniques.

\section{Results}

\section{The effects of bagging on peel thickness}

The peel plays an important role in protecting the fruit from outside stimulations [22, 23]. We measured the thickness of the peel to determine whether bagging alters the cellular structures. The epithelial cells of the NBF included 5-6 layers (Fig. 3a), while the upper epidermal cells of the bagging fruit (BFW and BFB) had only $4-5$ layers (Fig. $3 \mathrm{~b}-\mathrm{c}$ ), indicating that bagging changed the microenvironment around the fruit and reduced the number of cell layers in the peel.

The peel thickness of the BFW was only $0.031 \mathrm{~mm}$, which was significantly reduced (by 16.2\%) compared with NBF (Fig. 3d). However, the peel thickness of the BFB did not decreased, but increased significantly (by $16.0 \%)$ compared with the BFW, indicating that the cell walls of the peel were thickened.

The effects of bagging on the microstructure of peel cells We used transmission electron microscopy to determine the microstructure of the peel. The NBF and BFW fruits maintained the original tissue structure, with a uniform, complete and clear honeycomb structure, smooth and flat cell surface (Fig. 4a-b). The cellular structure of the BFB was obviously deformed and shriveled, the subcutaneous cells had begun to sag, the structure was loose and fluffy, the cellular structure was no longer honeycombed and complete, the surface tissue was broken, and the cellular structure was destroyed (Fig. 4c).

\section{Metabolomic analysis \\ Principal component analysis and metabolite intensity distribution assessment of QC samples}

To test the stability of the mass spectrometry system, we mixed (in equal proportions) samples to create QC samples. Firstly, we analyzed the principal components of QC samples; the PCA model diagram obtained through 7-fold cross-validation (seven cycles of cross-validation) is shown in Fig. 5a. The QC samples were closely clustered together, indicating that the experiment was stable and repeatable. Hierarchical clustering for the expression levels of all metabolites intuitively demonstrated the stability of the relationship between QC and other samples (Fig. 5b). There was no significant differences in the intensity distribution of metabolites between the $\mathrm{QC}$ and the other three samples, indicating a stable and accurate data.

\section{Determination of metabolites from the browning part of the peel}

We analyzed the differences of all metabolites in NBF, BFW, and BFB. Compared with NBF, 1775 and 2089 metabolites were significantly up-regulated and downregulated in BFW, respectively (Fig. 6a). Compared with BFW, 2211 and 2534 metabolites were significantly upregulated and down-regulated in BFB (Fig. 6b). To screen the marker metabolites, a combination of multidimensional and single-dimensional analysis was used. Differential metabolites with VIP $>1$ and $p$-value $<0.05$ were regarded as significantly differential metabolites. One hundred thirty-one metabolites of BFW were significantly up-regulation and 217 metabolites downregulation compared with NBF; 198 metabolites of $\mathrm{BFB}$
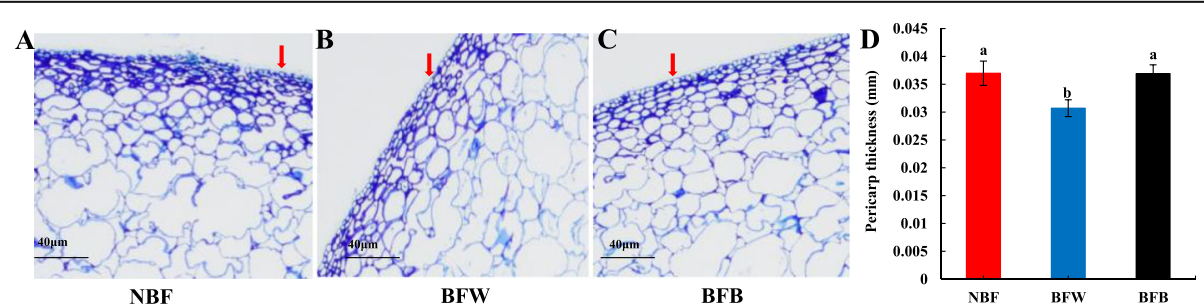

Fig. 3 The effect of bagging on peel thickness. Note: a: Unbagging fruit; b: Bagging fruit without browning; c: Bagging fruit with browning; $\mathbf{d}$ Thickness of apple peel 

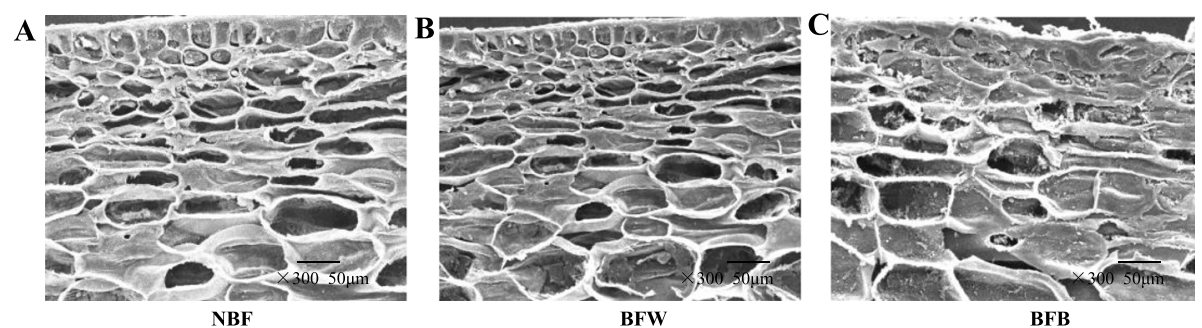

Fig. 4 The effects of bagging on the microstructure of peel cells. a: Bagging fruit without browning; $\mathbf{b}$ : Bagging fruit with browning

were significantly up-regulationand and 178 metabolites down-regulation compared with BFW.

\section{Screening of differential metabolites}

To investigate the relationship among samples and the differences in metabolites, a hierarchical clustering analysis was conducted on the expression levels of all those metabolites where a significant difference had been detected. According to the VIP value, a visual analysis was performed for the expression levels of the first top 50 differential metabolites. The results showed that, compared with NBF, 13 flavonoids (including apigenin, rutin, myricetin 3-glucoside, isoquercitrin, quercetin, quercetin 3-o-glucoside, phloridzin, 6-hydroxyluteolin 6-xyloside, procyanidin $\mathrm{B} 2$, quercetin 3 -arabinoside and morin were significantly decreased, clausarinol and gingerenone $\mathrm{B}$ were significantly increased), ten carbohydrate compounds (including lactulose, $d$-mannitol, sucrose, $d$-galactose, $d$-maltose, maltotriose, glucose 1-phosphate, fructofuranosy and 3-fucosyllactose were significantly increased, $d$-glucopyranoside was significantly decreased), ten lipid molecules ( $d$-glucopyranoside, hydroxypregn sulfate, 1-hexanol arabinosylglucoside, corchoionol C 9glucoside and vomifoliol were significantly decreased, 2hydroxyadipic acid, SM(d18:1/18:1(9Z)), scillirosidin, PI
(15:0/0:0) and C16 sphinganine were significantly increased), nine benzene ring-type compounds (including eugenol, anthraquinone and buclizine were significantly decreased, benzene-1,3,5-triol, thiabendazole, triphenylphosphate-thiabendazole, pandamarilactam-3x, citbismine $\mathrm{C}$ and pterosin $\mathrm{H}$ were significantly increased), five organic acids and their derivatives (including raltitrexed, isocitrate and 1-o-p-coumaroyl-beta-d-glucose were significantly increased, ustiloxin D and oxane-2-carboxylic acid were significantly decreased), one scatterbrained lipid (armillaripin was significantly increased) and two other types metabolites (including 2,2-dichloro-1,1-ethanediol was significantly increased, atorvastatin was significantly decreased) had significantly changed in BFW (Fig. S1A, Table S1).

The differential metabolites were further subdivided. The down-regulated differential metabolites were mainly flavonoids in BFW compared with NBF. It is well known that most plants contain flavonoids [24], which play an important role in plant growth. As a kind of secondary metabolite, flavonoids can remove free radicals and delay the normal tissue cell apoptosis [25]. However, flavonoids were not included among the up-regulated metabolites in BFW. To determine the causes of browning, or the substances produced by browning, the metabolites were detected in BFB and BFW groups. Among the
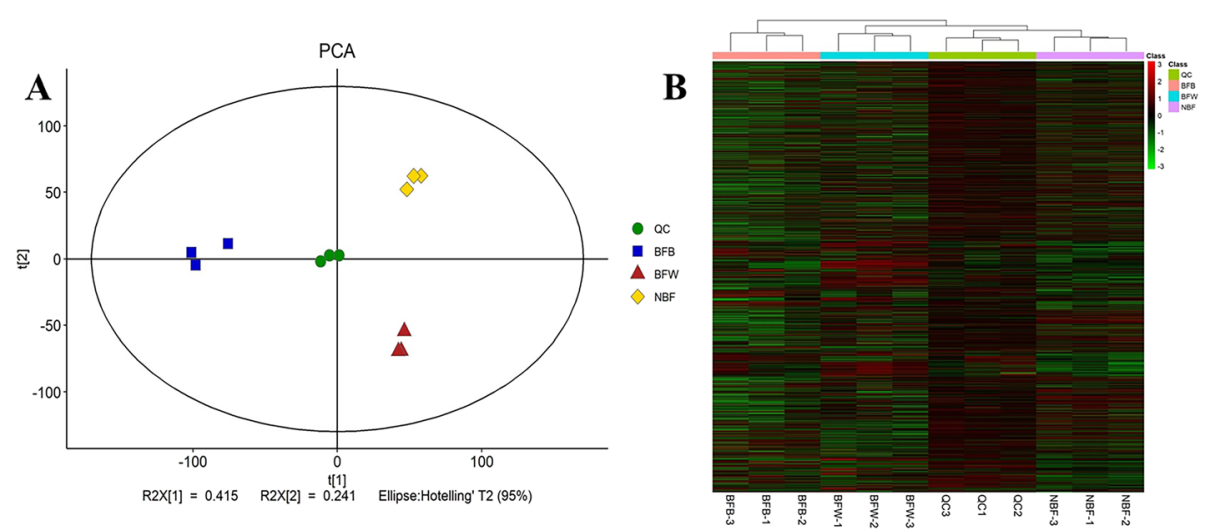

Fig. 5 Principal component analysis of QC samples and analysis of metabolite strength distribution. Note: $\mathbf{a}$ : PCA model figure; b: Hierarchical clustering Fig. QC: Quality control; BFB: Bagging fruit with browning; BFW: Bagging fruit without browning; NBF: Unbagging fruit 

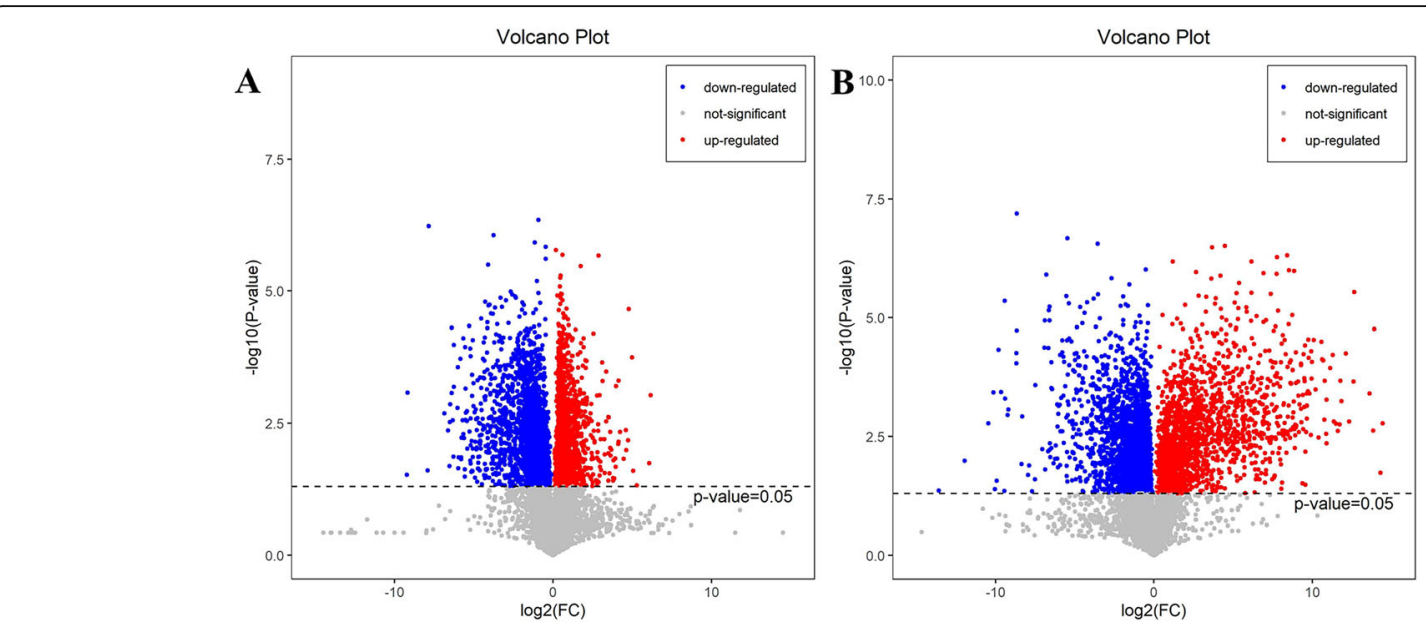

Fig. 6 The effect of fruit peel browning on metabolites. a: BFW-NBF group; b: BFW-BFB group. Note: The red origin represents the significantly up-regulated differential metabolites in the experimental group, the blue origin represents the significantly down-regulated differential metabolites, and the gray point represents no significant difference

significantly changed metabolites (Fig. S1B), we identified 12 flavonoids (including procyanidin-B2, phloridzin, hydroxyluteolin, quercetin 3-arabinoside, gingerenone B, quercetin-3-o-glucoside, isoquercitrin, quercitrin, morin and clausarinol were significantly decreased, eurycomanone and marmesin galactoside were significantly increased), 13 triterpenes (including ganosporeric acid A was significantly decreased, medicagenic acid, 12oleanadien-28-oic acid, esculentic acid, oxane-2carboxylic acid, phytolaccinic acid, ganolucidic acid B, protobassic acid, ganolucidic acid E, 16alpha-hydroxygypsogenic acidid, pokeberrygenin and corosin were significantly

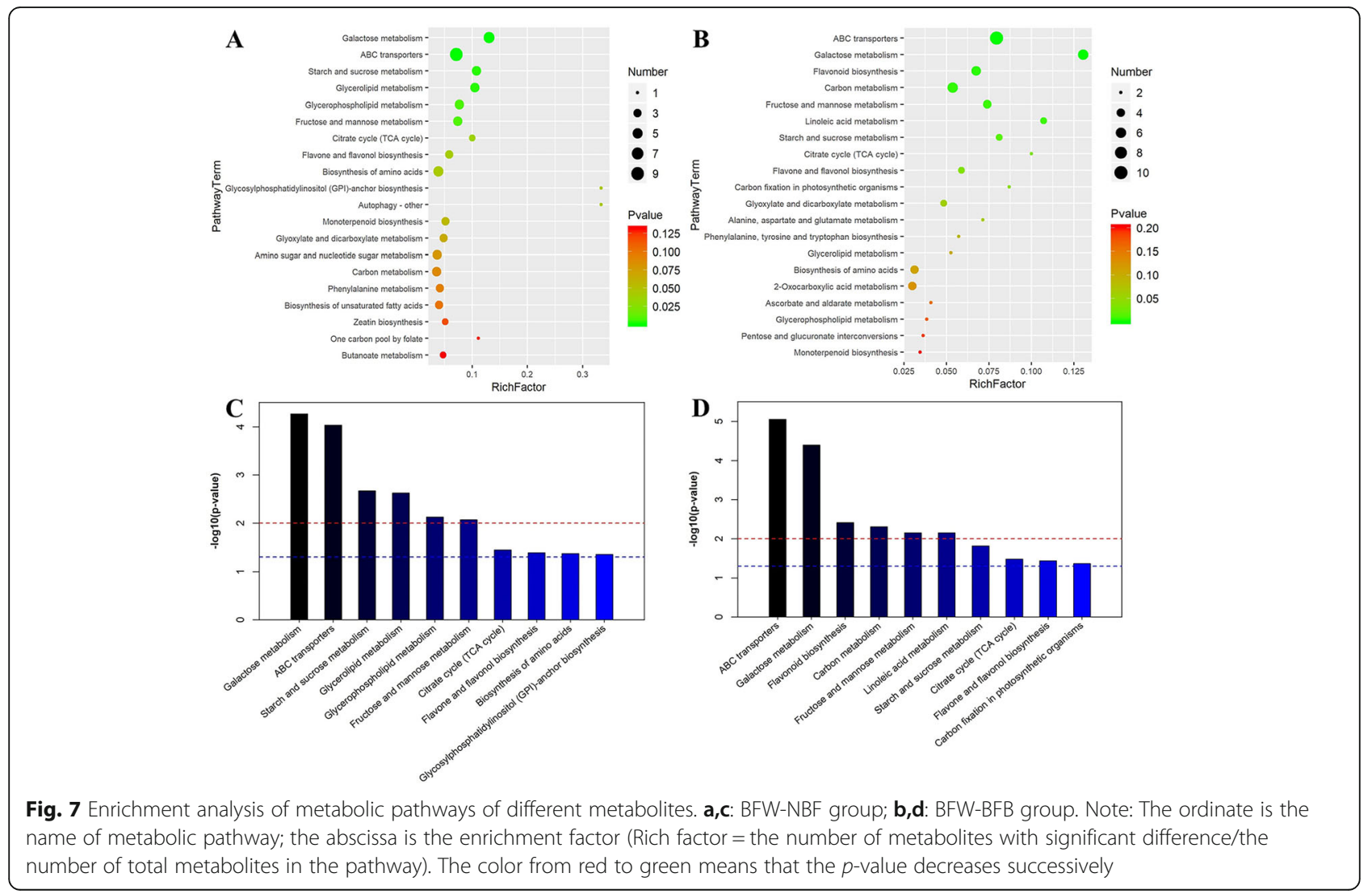


increased), 11 lipids and their associated molecules (including SM(d18:1/18:1(9Z)), C16-sphinganine, scillirosidin, estradiol17beta-3-sulfate, 2-hydroxyadipic acid and vomifoliol, tetranor-PGDM were significantly decreased, physalolactone B, EB-1213, pentanorcholecalciferol and cyclo-cholest were significantly increased), 7 organic acids and their derivatives (including chlorogenic acid, feruloyl C1-glucuronide, cis-5caffeoylquinic acid, raltitrexed and quinic acid were significantly decreased, acety-l-tributy-l-citrate and isocitrate were significantly increased,), 4 sugar compounds (including $d$ maltose, $d$-Fructofuranosyl, 3-fucosyllactose and sucrose were significantly decreased), 2 benzene ring-type compound derivatives (including citbismine $\mathrm{C}$ was significantly decreased, C2-(4-Methyl-1,3-pentadienyl) anthraquinone was significantly increased), 1 lipid (armillaripin was significantly decreased), and 1 other compound ((17Z)-1 $\alpha, 25$-dihydroxy26,27-dimethyl-17,20,22,22,23,23-hexadehydrocholecalciferol was significantly increased) had significantly changed in BFB (Fig. S1B, Table S2).

\section{Enrichment analysis of differential metabolites}

To understand the differential metabolic pathways of various samples by comparing the differential metabolites in the Kyoto Encyclopedia of Genes and Genomes
(KEGG, https://www.kegg.jp/) database, the top 20 metabolic pathways with significant enrichment were selected for bubble mapping (Fig. 7). Galactose metabolism, $\mathrm{ABC}$ membrane transporter protein, starch and sucrose metabolism, glyceride/phospholipid metabolism, and fructose and mannose metabolism were significantly changed in BFW compared with NBF (Fig. 7a-c).

To better understand the final major metabolites and metabolic pathways of bagging-induced fruit browning, we conducted enrichment analysis of differential metabolites and metabolic pathways in BFW and BFB. Multiple metabolic pathways were significantly changed in BFB compared with BFW: $A B C$ membrane transporter, galactose metabolism, flavonoid biosynthesis, carbon metabolism, fructose and mannose metabolism, and linoleic acid metabolism (Fig. 7b-d). Based on the top 50 differential metabolites, the inhibition of flavonoid biosynthesis leads to the decrease of antioxidant substances, which is directly responsible for fruit browning, while the damage of the cell membrane might be the direct cause of the inhibition of flavonoid biosynthesis and transport.
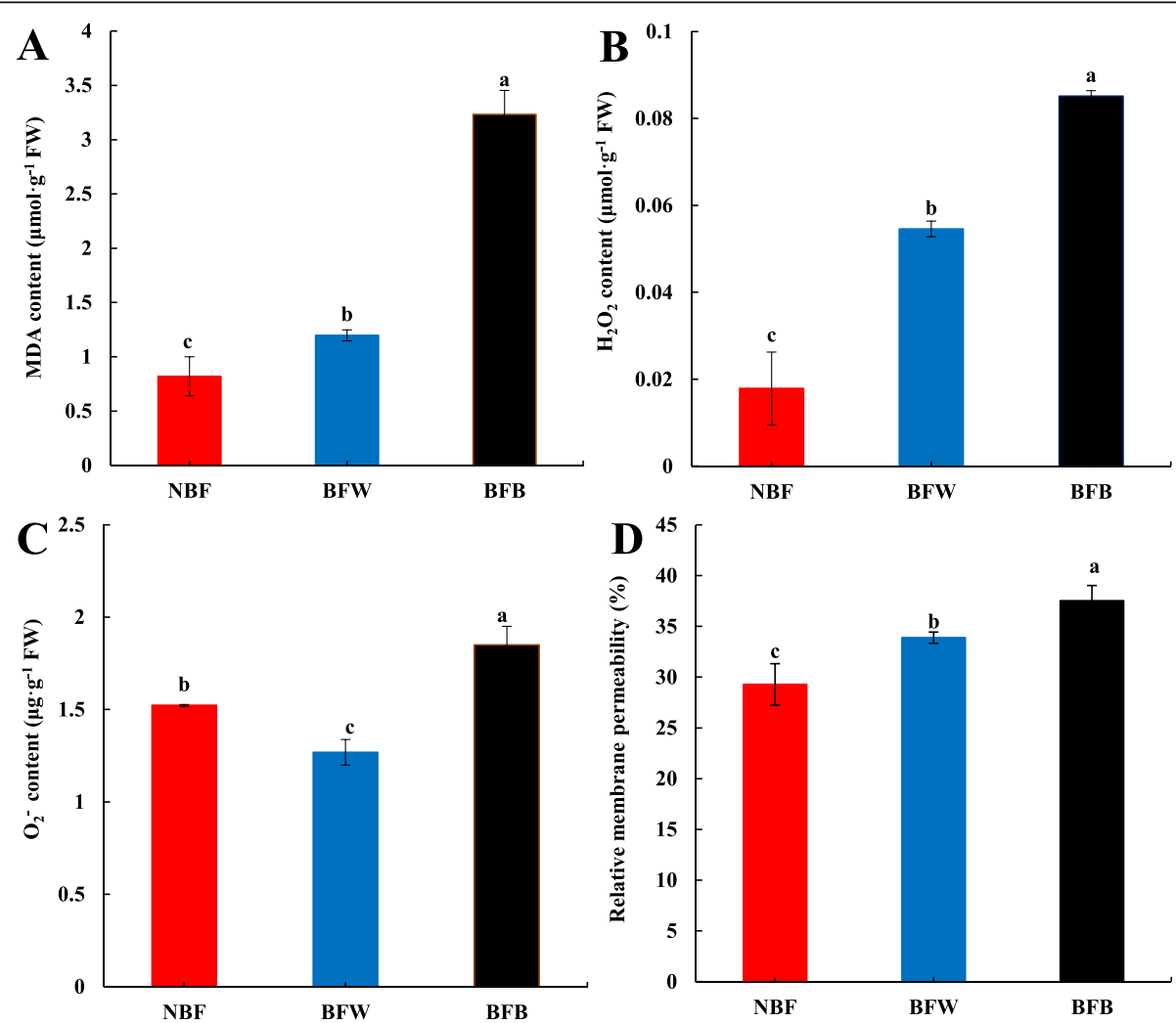

Fig. 8 The relationship between membrane lipid peroxidation and peel browning. a: Malondialdehyde content (MDA); b: Relative membrane permeability; c: Hydrogen peroxide content $\left(\mathrm{H}_{2} \mathrm{O}_{2}\right)$; d: Superoxide anion content $\left(\mathrm{O}_{2}^{-}\right)$. Error bars represent the averages of three biological replicates \pm SD. Different letters represent differences between different processes. (Significance was defined as $P<0.05$ ), same as the below 
The effects of bagging on membrane lipid peroxidation

By measuring the microstructure of the peel, we determined that the browning after bagging was closely related to the integrity of the cell structure. We further measured the degree of membrane lipid peroxidation. Compared with NBF, the MDA content in peel of BFW and $\mathrm{BFB}$ were significantly increased by 0.46 times and 2.94 times, respectively (Fig. 8a); the $\mathrm{H}_{2} \mathrm{O}_{2}$ content in BFW and BFB were significantly increased by 2.05 times and 3.75 times, respectively (Fig. $8 \mathrm{~b}$ ); and the $\mathrm{O}_{2}{ }^{-}$content was significantly decreased $16.6 \%$ in BFW, but significantly increased $21.5 \%$ in BFB (Fig. 8c). This finding indicated that the peroxidation of the cell membrane was accelerated by the microenvironment changes after bagging. We also measured the cell membrane permeability and found that, compared with NBF, the cell membrane permeability of BFW and BFB were significantly increased by 15.7 and $28.2 \%$, respectively (Fig. 8d).

\section{The effects of bagging on the activities of SOD, CAT and $P O D$}

SOD, CAT and POD, the key active oxygen-scavenging enzymes, can scavenge ROS and prevent the accumulation of ROS [26-28]. As shown in Fig. 9, the activities of SOD, CAT and POD were significantly influenced after bagging. Compared with NBF, the activities of SOD and CAT in BFB were significantly decreased 82.3 and $30.1 \%$, respectively, there were a downward trend, but no significances in BFW (Fig. 9a-b). Besides, the activities of POD was significantly decreased after bagging, compared with NBF, the activity of POD in peel of BFW and BFB were significantly decreased 73.2 and $73.3 \%$, respectively (Fig. 9c).

\section{The effects of bagging on the antioxidant capacity of the peel}

Based on metabolomics analysis, bagging significantly reduced the accumulation of antioxidant substances in the peel, inhibited the synthesis of flavonoids after browning. To further verify whether the decrease in antioxidant leading to the browning, we measured the content of total phenols (TP), total flavanols (TFA), and total flavonoids (TFO) in the peel. As shown in Fig. 10, after bagging, the accumulation of antioxidant substances was significantly reduced, and the reduction degree in BFB was more significant. Compared with NBF, the contents of TP and TFO were significantly reduced 12.6 and 5.1\% in BFW, respectively, and the content of TFA showed a decreasing but not significant trend. Compared with NBF, the contents of TP, TFO, and TFA in the BFB were significantly reduced $38.6,35.1$ and $28.0 \%$, respectively.

\section{The effects of bagging on the phenolic acid composition of the peel}

Phenolics acid in fruits and vegetables have gained much attention because of their antioxidant activities and their beneficial implications for human health [29]. By measuring the phenolic acid composition in the peel, we found that, after bagging, the phenolic acid in the peel was significantly reduced. As shown in the Fig. 11, compared with NBF, especially, the contents of catechin, epicatechin, procyanidin B1, procyanidin B2, rutin, monohydric acid, quercitrin, gallate in BFW were significantly reduced 25.8, 24.6, 10.1, 12.1, 34.1, 17.2, 21.1, $22.6 \%$, respectively; after the peel browning, these substances content in BFB were significantly decreased 42.1, $41.6,25.1,29.7,65.0,52.1,57.9,45.3 \%$, respectively. It further explained that, bagging affected the accumulation of antioxidant in peel.

\section{Analysis the gene expression of related-flavonoids}

As shown in Fig. 12, compared with NBF, the flavonoid synthesis genes $M d C H S, M d F 3 H, M d D F R, M d A N S$ and $M d U F G T$ were significantly down-regulated in BFW and $\mathrm{BFB}$, while the $M d L A R$ genes were significantly upregulated by 2.55 and 9.37 times in BFW and BFB, and the $M d A N R$ genes were significantly up-regulated by
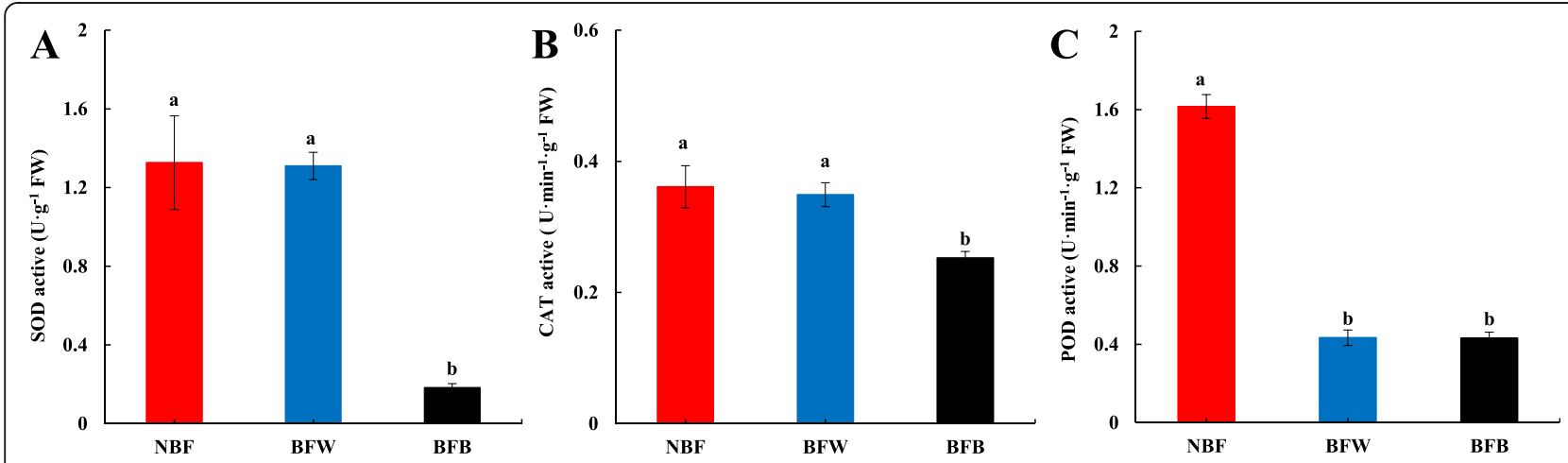

Fig. 9 The effects of bagging on the activities of SOD, CAT and POD. a: Superoxide dismutase (SOD); b: Catalase from micrococcus lysodeiktic (CAT); c: Peroxidase (POD) 

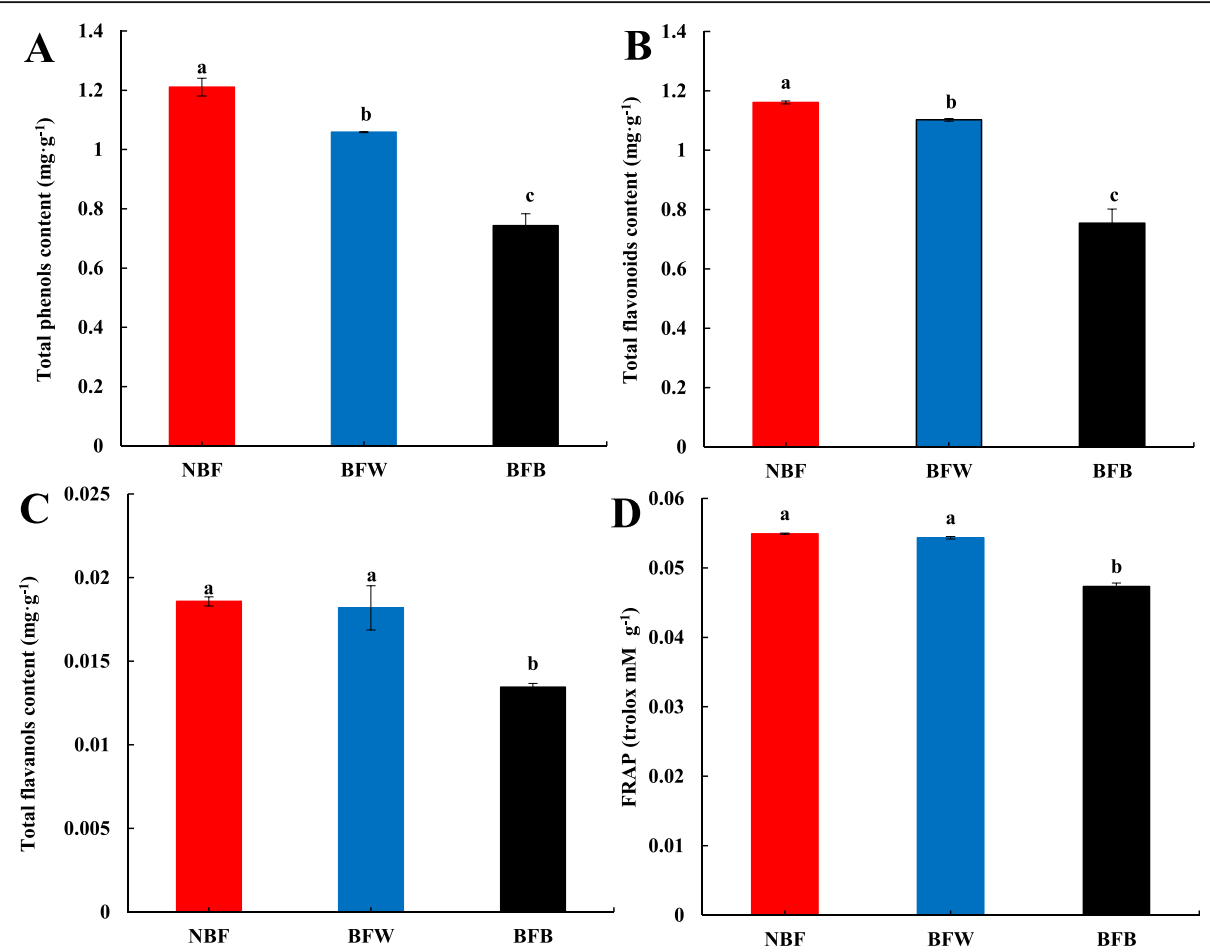

Fig. 10 Relationship between antioxidant capacity and browning of peel

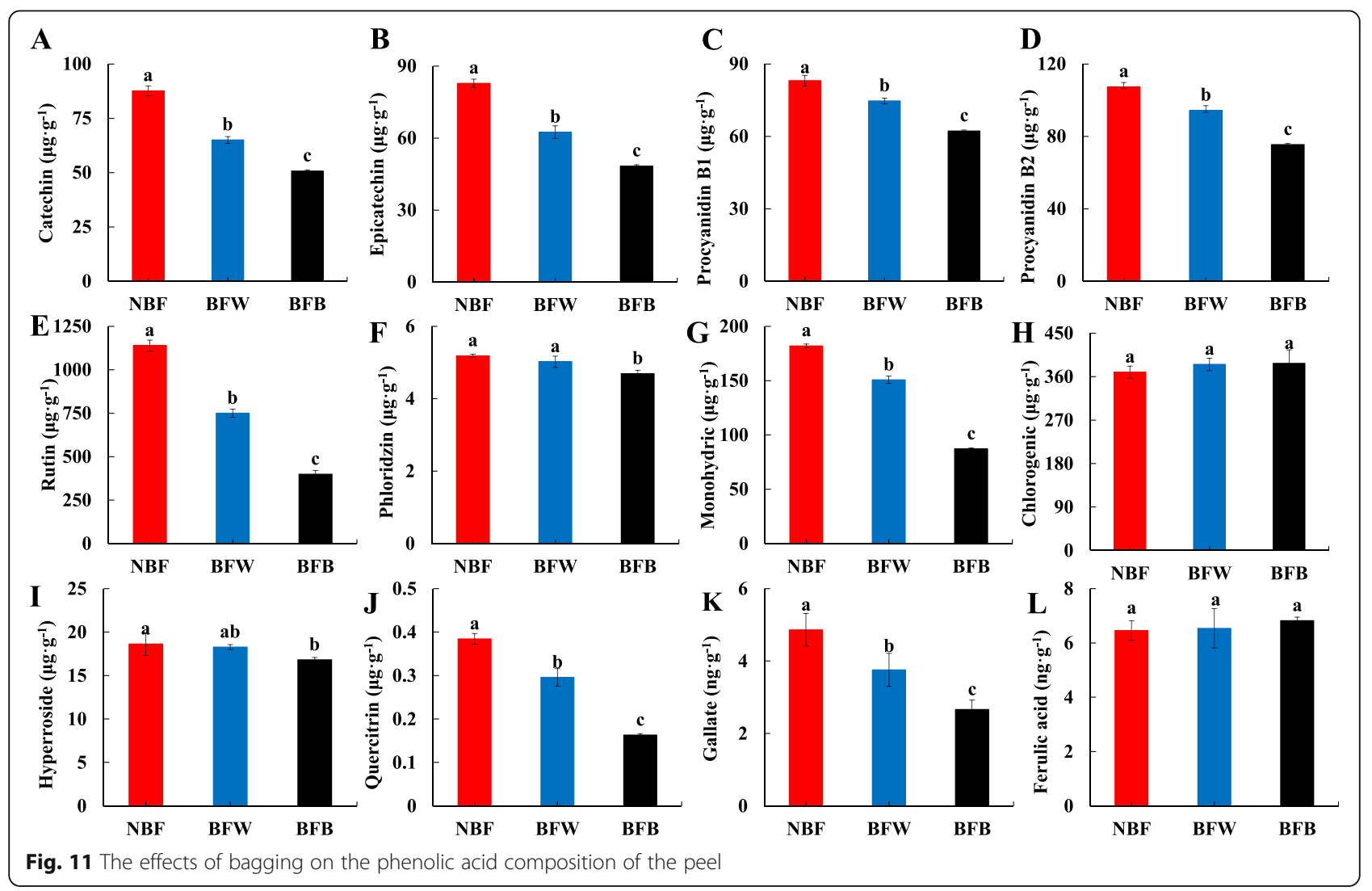




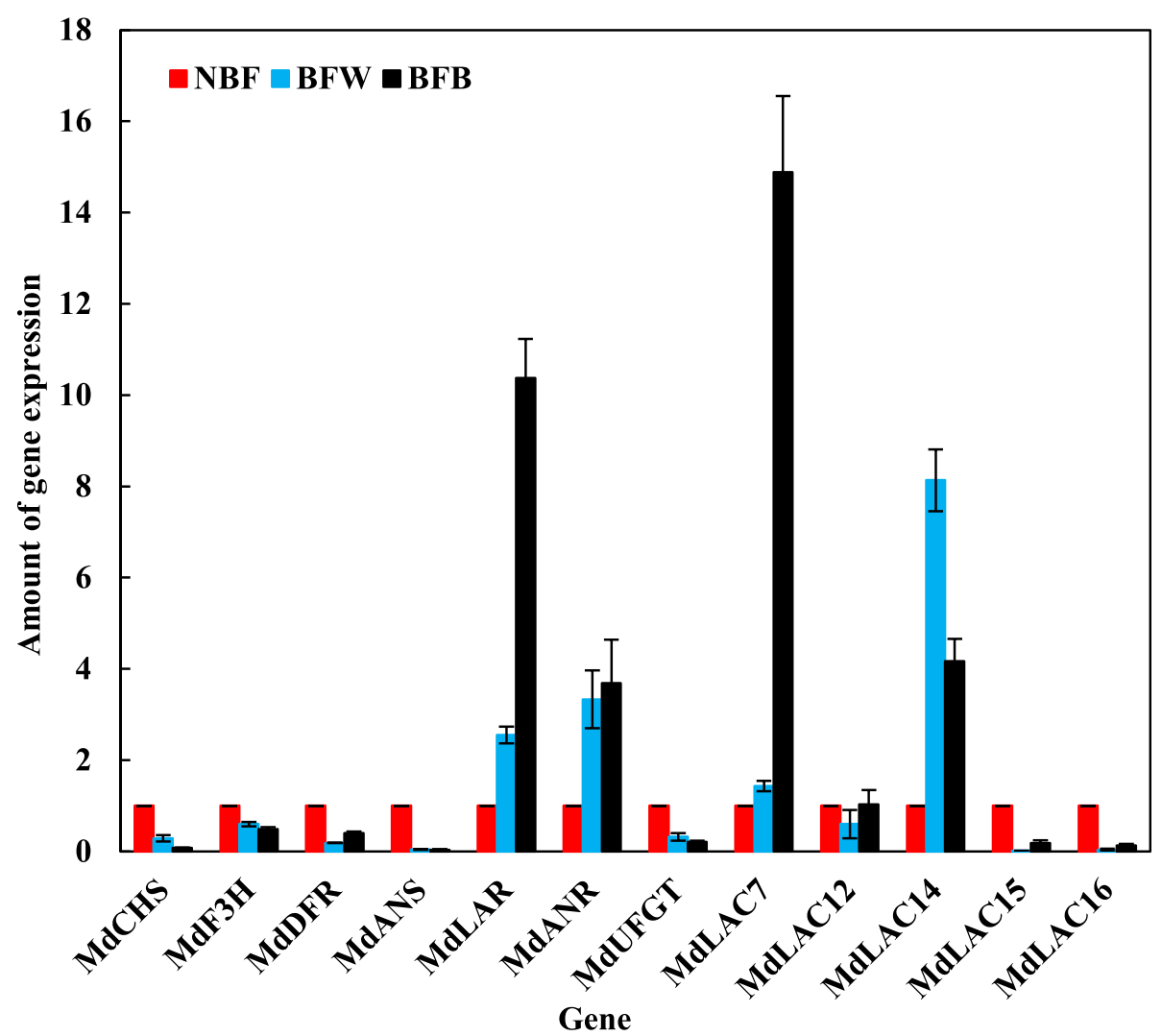

Fig. 12 Analysis the gene expression of related-flavonoids

2.33 and 2.69 times in BFW and BFB, respectively. Interestingly, with the high expression of flavonoids-related synthetic genes, the downstream flavonoids-related polymeric genes were also highly expressed, among which $M d L A C 7$ and MdLAC14 were the most significantly expressed. Compared with NBF, MdLAC7 was significantly up-regulated by 0.43 and 13.88 times in BFW and $\mathrm{BFB}$, and MdLAC14 was significantly up-regulated by 7.13 and 3.17 times in BFW and BFB, respectively.

\section{Discussion}

Browning in fruit, including enzymatic and nonenzymatic, the occurrence of enzymatic browning is closely related to the integrity of cell membrane. Enzymatic browning is induced by enzymes distributed in the elastoplast and substrates [30]. When cells suffered from stress, the ability of the fruit to clear free radicals was decreased, which lead to the accumulation of reactive oxygen species $\left(\mathrm{O}_{2}{ }^{-}\right)$, accelerated membrane lipid peroxidation, and increased membrane permeability [30]. This conclusion is consistent with the results we have measured (Fig. 8), after bagging, more $\mathrm{H}_{2} \mathrm{O}_{2}, \mathrm{O}_{2}{ }^{-}$and MDA were produced in the peel, which accelerated the destruction of cell structure. In addition, previous studies have found that the oxidation of chlorogenic acid by the enzyme polyphenol oxidase (PPO) is the key factor in the symptoms of the peel browning [31, 32]. During storage at low temperature, the cellular organelle' internal membranes was destroyed, promoting the reaction between PPO (stored in the plastid) and chlorogenic acid (stored in the vacuole), leading to the production of quinones and melanin, which finally resulting in the dark-discolored areas on the fruit peel $[20,33]$. Wang studied that, such as in the no browning peel of apple, its high expression of chlorogenic acid content, may be associated with inhibition of peel browning, exogenous chlorogenic acid treatment significantly enhanced the expression of genes involved in the biosynthesis of flavonoids, lignin synthesis gene was inhibited expression [34]. But, our results showed that endogenous chlorogenic acid content did not reduce with browning (Fig. 11), so, we thought that chlorogenic acid was not the most suitable substrate for enzymatic browning in before-harvest.

It is well known, flavonoids are major secondary metabolites, including anthocyanin, flavone, flavonol, procyanidins, isoflavone, and orange ketone different subgroups [35], which play a series of roles in cells, inducing color changes and improving the antioxidant ability of the plant [36, 37]. Flavonoids are synthesized 
in plants through the phenylephrine metabolic pathway, starting from phenylalanine and catalyzed by the phenylalanine ammonialyase ( $P A L)$ to form cinnamic acid, then forms $p$-coumary-coa catalyzed by cinnimate 4hydroxylase $(\mathrm{C} 4 \mathrm{H})$ and 4-coumarate coa ligase $(4 \mathrm{CL})$. Under the joint action of chalcone synthase (CHS), chalcone isomerase $(\mathrm{CHI})$, flavanone 3-hydroxylase $(F 3 H)$, and flavanone 3-hydroxylase $(D F R), p$-coumaniol-coa is transformed into flavonoid products [38]. The downstream structural gene $L A C$ has been proved that its closely related to the oxidative polymerization of flavonoids on the phenylephrine metabolic pathway [39]. Previous studies have shown that laccase ( $p$-diphenol: $\mathrm{O}_{2}$ oxidoreduacatse, E. C 1.10.3.2) encoded by $L A C$ is directly related to the fruit browning [40]. Laccase as an intracellular enzyme, which is involved in the biosynthesis of lignin, capable of monolol oxidative polymerization, and participates in the polymerization of flavonoid substances [40]. The laccase encoded by TT10 in the model plant Arabidopsis, as a flavonoid oxidase to catalyze oxidative polymerization of epicatechin to produce yellow and brown pigments different from colorless proanthocyanidins [41]. Epicatechin and procyanidin secreted into plasmids can be interpreted that in the process of seed dry cell death caused by broken vacuole, and epicatechin and former cyanine glycosides interact with TT10, originally colorless former cyanine glycosides and cell wall polysaccharides and other phenolic compounds form oxide compounds, can easily lead to organization dim [39]. Some laccase genes (such as LAC14 and LAC15) also had a higher expression in the peel of fruit rust [42, 43]. In litchi, $A D E / L A C$ is located in vacuoles and transported to the cell wall to function, and oxidative polymerization with catechin in peel occurs, accelerating degradation of procyanidins and promoting browning of peel [39]. It is interesting to note that laccases have a wider substrate range than PPO [44]. Similar to related PPO, laccases are capable of oxidizing not only $o$-diphenols, but also $p$-diphenols, methoxy-substituted monophenols, diamines and nonaromatics, despite the mechanism for many of these reactions has not been elucidated [45]. In our study, it was found that in the process of browning, $M d L A C 14$ was also expressed along with the high expression of $M d L A C 7$, and we speculated that there was an interactive relationship between $M d L A C 7$ and MdLAC14. While, the content of catechin, epicatechin and proanthocyanidin were significantly decreased with browning, so, we believe that these compounds may be substrates for the new enzymatic browning induced by laccase. But, the specific molecular mechanism needs us to explore. Figure 13 shows the metabolic pathway of flavonoids.
In addition, through the analysis of metabolome data, we also found an interesting thing: after bagging, more triterpenes enriched in $\mathrm{BFB}$, while the accumulation of triterpenes was not obvious in the peel of NBF or BFW. Terpenoids are widely found in nature and are the main components of some plant essences, resins, and pigments (such as rose oil, eucalyptus oil, turpentine) [4648]. For instance, ganolucidic acid, first proposed by Kubota et al. [49], which is a highly oxidized lanolin triterpenoid, a triterpenoid commonly found in ganoderma lucidum. It is generally yellow-brown and has a very bitter taste [49]. So, we suspect that the excessive expression of triterpenes in the peel might be principally responsible for peel browning. Besides, the high expression of $M d L A C$ was not only directly related to the decrease of flavonoids, but also related to the oxidative polymerization of terpenoids in fruits at maturity stage? The effect of bagging on the synthesis of triterpenes remains to be studied.

\section{Conclusions}

In summary, the results of this study indicated that the destruction of cell structure, the increase of lipid peroxidation of cell membrane, the decrease of flavonoids and the increase of triterpenoids were the main reasons for the browning of peel about bagging 'Rui Xue'. What's more, whether a direct relationship between the high $M d L A C$ expression, the decrease of flavonoids and the increase of triterpenes requires further investigations.

\section{Materials and methods}

\section{Experimental design}

The experiment was conducted at the Bai Shui County Apple Test Station of Northwest A \& F University $\left(35^{\circ} 2^{\prime}\right.$ $\mathrm{N}, 109^{\circ} 6^{\prime} \mathrm{E}$ ) from May to October in 2019. The test station owns a warm temperate continental monsoon climate with an altitude of $915 \mathrm{~m}$, annual mean rainfall of $578 \mathrm{~mm}$, and an annual mean temperature of $11.4^{\circ} \mathrm{C}$. In the middle and late stage of fruit growth, the maximum temperature of atmosphere and inner bag in the daytime was $31.7^{\circ} \mathrm{C}$, the relative humidity was 40.7 and $35.9 \%$, respectively, the minimum temperature at night was $4.1{ }^{\circ} \mathrm{C}$ and $4.6^{\circ} \mathrm{C}$, respectively, and the relative humidity was $100 \%$, the details of the date are given in Supplemental Fig. S2. Scions of 'Rui Xue' were grafted to M26 roots stocks. 5-year-old fruit trees of 'Rui Xue' were used as materials ('Rui Xue' has passed the national cultivar certification in China. The trees and bud wood under rules of International Plant Variety Rights are available for research purposes, which can be obtained from Zhengyang Zhao at Northwest A\&F University. The number of cultivar is CNA20151469.1). The trees were cultivated as spindle-shaped $(1.5 \times 3.0 \mathrm{~m})$. Bagging was 


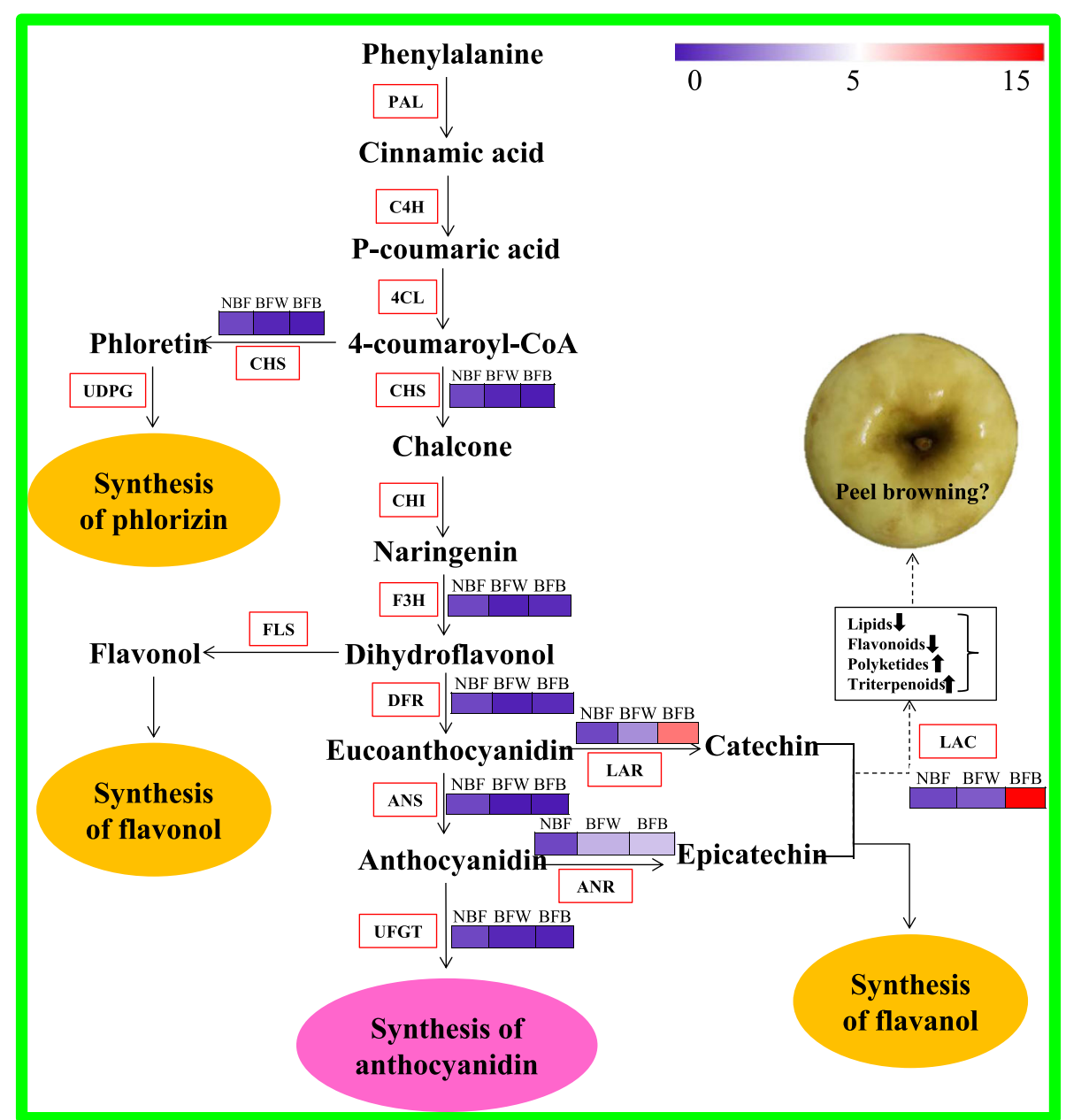

Fig. 13 The metabolic pathway of flavonoids. Note: The color from purple to red means that gene expression increase successively. PAL: Phenylalanine ammonia-lyase; C4H: Cinnamate 4-hydroxylase; 4CL: 4-coumarate coenzyme A ligase; CHS: Chalone synthase; CHI: Chalcone isomerase; F3H: Flavanone 3-hydroxylase; DFR: Dihydroflavonol reductase; ANS: Anthocyanidin synthase; LAR: Leucoanthocyanidin reductase; ANR: Anthocyanidin reductase; UFGT: UGP glucose-flavonoid3-o- glucosyl; LAC: P-diphenol dioxygen oxidoreductase

conducted in middle of May 2019. The external bag was brown and the inner was red (the specification of fruit bags was $155 \mathrm{~mm} \times 180 \mathrm{~mm}$, the outer paper was $57.0 \mathrm{~g}$ wood pulp composite paper, the outer color was pulp color, and the inner color was black, the inner paper was $32.0 \mathrm{~g}$ red paper coated with wax on both sides). Three rows of bagging and without bagging fruits were set as biological repeats, with ten plants in each line. The fruits were harvested with bags at the mature stage (October, 2019). The bagging fruits without browning (BFW) and bagging fruits with browning (BFB) were randomly selected as the experimental group, non-bagging fruits (NBF) were used as the control (CT). Thirty fruits with the same size, maturity, and without any mechanical damage were selected for analysis for each group. The fruit peels of the stalk cavity were sampled with a sterilized scalpel, and then immediately frozen in liquid nitrogen and stored at $-80^{\circ} \mathrm{C}$.

\section{Methods}

Classification of apple peel browning

According to the methods of Chen [17] (slightly modified), the bagged fruits were classified into five levels according to the browning area (expressed by $\mathrm{S}$ ) of the peel (Fig. 1):

0 , there was no brown spot on the surface of fruit;

I, the browning area was $0<\mathrm{S} \leq 1 / 5$;

II, the browning area was $1 / 5<\mathrm{S} \leq 1 / 4$;

III, the browning area was $1 / 4<\mathrm{S} \leq 1 / 3$;

IV, the browning area was $1 / 3<\mathrm{S} \leq 1 / 2$;

$\mathrm{V}$, the browning area was $1 / 2<\mathrm{S} \leq 1$.

\section{Peel thickness}

The thickness of the peel was determined by the paraffin section method [50]. Each peel section in every group was randomly selected at three different positions of the stalk cavity peel. The whole area of tissues was pictured 
under a 100-fold field of view, so as to ensure the consistent background light of each photo. We chose the outer three layers of cells as the critical for measuring the thickness of the peel. Image-pro Plus 6.0 (Media Cybernetics, Inc., Rockville, MD, USA) was used to measure the thickness $(\mathrm{mm})$ of epidermis at five points of each slice with a 100 -fold scale as the standard.

\section{Microstructure of the peel cells}

The ultrastructure of cells was determined according to the method described by Chen [17]. The peel flakes were fixed on the glass-covered with $4 \%$ glutaraldehyde for 5 $\mathrm{h}$ and washed with ethanol with an increasing gradient (10-100\%) for $10 \mathrm{~min}$. Each piece of tissue was soaked in $100 \%$ ethanol for $10 \mathrm{~min}$ and then stored overnight in a dryer. The completely dehydrated tissues were transferred to the double-sided carbon-belted aluminum pile in a vacuum, then sputtered and gilded, and finely sliced. The visualized 3D model was analyzed at $20 \mathrm{kV}$ using a scanning electron microscope (FEI Quanta 200, Thermo Fisher Scientific, Bedford, MA, USA).

\section{Metabolites profiling}

An ACQUITY UPLC ultra-high-performance liquid phase series AB Triple TOF 5600 high-resolution mass spectrometer was used to determine liquid-mass coupling. For the determination, $80 \mathrm{mg}$ samples were taken. Then, the internal standard $(20 \mu \mathrm{L})(\mathrm{L}-2$-chlorophenylalanine, $0.3 \mathrm{mg} / \mathrm{mL}$; Lyso PC17:0; $0.01 \mathrm{mg} / \mathrm{mL}$, all solutions were configured with methanol) and $1.0 \mathrm{~mL}$ methanol:water $(\mathrm{V}: \mathrm{V}=7: 3$, contains $0.01 \mathrm{~mol} / \mathrm{L}$ BHT $(2$, 6-di-tert-butyl-p-cresol)) were mixed. Then, two small steel balls were added, and the sample pre-cooled at $20^{\circ} \mathrm{C}$ for $2 \mathrm{~min}$ before being placed in the grinding machine $(60 \mathrm{~Hz}, 2 \mathrm{~min})$. After $30 \mathrm{~min}$ of ultrasonic extraction, the sample was left to stand at $-20^{\circ} \mathrm{C}$ for $20 \mathrm{~min}$, then centrifuged for $10 \mathrm{~min}\left(13,000 \mathrm{rpm}, 4^{\circ} \mathrm{C}\right)$. The supernatant $(300 \mu \mathrm{L})$ and shake it dry, then use $400 \mu \mathrm{L}$ methanol:water $(\mathrm{V}: \mathrm{V}=1: 4)$ to redissolve it, vortex for 30 $\mathrm{s}$, and ultrasound for $2 \mathrm{~min}$. After centrifugation for 10 $\min \left(13,000 \mathrm{rpm}, 4^{\circ} \mathrm{C}\right)$, using a syringe to absorb $150 \mu \mathrm{L}$ of the superfluid, and using $0.22 \mu \mathrm{L}$ of the organic phase pinhole filter to filter it. Then, the filtered organic phase was transferred to the LC injection vial and stored at $80{ }^{\circ} \mathrm{C}$ until LC-MS analysis. Three biological repeats were tested in each group. The quality control sample (QC) was prepared by mixing an equal volume of the extract of all samples; the final volume of each QC was the same as the sample volumes. All extracted reagents were pre-cooled at $-20^{\circ} \mathrm{C}$ before use.

\section{Membrane lipid peroxidation}

MDA was measured according to the method described by Sun [51] (with minor modifications). We took $1.0 \mathrm{~mL}$ of the sample supernatant extracted above and added $2.0 \mathrm{~mL} 0.67 \%$ thiobarbituric acid (TBA). Samples containing only $1.0 \mathrm{~mL}$ water were set as a negative control. Next, the samples were placed in a boiling water bath for $15 \mathrm{~min}$, and then rapidly cooled by immersion in cold water, and poured them into $10 \mathrm{~mL}$ centrifuge tubes. All tubes were centrifuged at $400 \mathrm{rpm}$ for $20 \mathrm{~min}$ and determining the absorbance of all samples at $600 \mathrm{~nm}$, $532 \mathrm{~nm}$, and $450 \mathrm{~nm}$ used a spectrophotometer.

$\mathrm{O}_{2}{ }^{-}$was measured according to the method described by Zhao [52] (with minor modifications). Two point zero grams fresh samples were weighed, then, using 65 mmol. $\mathrm{L}^{-1}$ phosphate buffer ( $\mathrm{pH}$ 7.8) to extract, constant volume to $10 \mathrm{ml}$, centrifuged (10,000 rpm, $10 \mathrm{~min}$ ), and the supernatant was extracted for later use. Extracting $2.0 \mathrm{ml}$ of supernatant, then, adding $1.5 \mathrm{ml}$ of phosphate buffer and $0.5 \mathrm{ml}$ of hydroxylamine hydrochloride, mixing and keeping warm in water bath at $25^{\circ} \mathrm{C}$ for $20 \mathrm{~min}$. Extracting $2.0 \mathrm{ml}$ supernatant after bathed, adding $2.0 \mathrm{ml}$ $7 \mathrm{mmol} \cdot \mathrm{L}^{-1} \alpha$-naphthylamine and $2.0 \mathrm{ml} 17 \mathrm{mmol} \cdot \mathrm{L}^{-1}$ sulfanilic acid, bathing at $30^{\circ} \mathrm{C}$ for $30 \mathrm{~min}$, measuring the absorbance of all samples at $530 \mathrm{~nm}$ used a spectrophotometer.

The content of $\mathrm{H}_{2} \mathrm{O}_{2}$ was measured according to the method described by Zhao [52]. Two point zero grams of fresh plant tissue was weighed, adding $2.0 \mathrm{ml}$ of precooled acetone. Then, centrifugation at $3000 \mathrm{rpm}$ for 10 min. Then, extracting $0.3 \mathrm{ml}$ supernatant, adding $0.1 \mathrm{ml}$ of $5 \%$ titanium sulfate and $0.2 \mathrm{ml}$ of concentrated ammonia, centrifuged (3000 rpm $10 \mathrm{~min}$ ), then, the precipitation with acetone repeated washing $3 \sim 5$ times, adding $5.0 \mathrm{ml}$ sulfuric acid $\left(2.0 \mathrm{mmol} \cdot \mathrm{L}^{-1}\right)$, after being completely dissolved, measuring the absorbance of all samples at $415 \mathrm{~nm}$ used a spectrophotometer.

Cell membrane permeability was measured according to a simplified method [52]. Briefly, fruits were cleand with tap water, and then rinsed twice with distilled water. Zero point five grams peel of stalk cavity was taken into $50 \mathrm{ml}$ centrifugal tube, $20 \mathrm{ml}$ of distilled water added, shaking. Then the conductivity was measured using DDS-307 conductivity meter (Shanghai Precision Scientific Instrument Co. Ltd., Shanghai, China). The nozzle seals were put in a boiling water bath for $10 \mathrm{~min}$, cooled by tap water, shaken and conductance measured according to the formula to calculate the cell membrane permeability.

\section{The activities of SOD, CAT and POD}

The activities of SOD, CAT and POD were measured according to the method described by Zhao [52]. Briefly, $0.5 \mathrm{~g}$ fresh sample was weighed, adding $4.0 \mathrm{ml}$ phosphate buffer $\left(0.05 \mathrm{~mol} \cdot \mathrm{L}^{-1} \mathrm{pH} 7.8\right)$ to extract, then, centrifuged $\left(4{ }^{\circ} \mathrm{C} 3000 \mathrm{rpm} 10 \mathrm{~min}\right)$, all extracted reagents were precooled at $-20^{\circ} \mathrm{C}$ before use. The SOD activity was 
Table 1 The primer sequences for real-time PCR

\begin{tabular}{|c|c|c|c|}
\hline Gene name & Gene ID & Forward primer sequence & Reverse primer sequence \\
\hline MdActin & MD12G1140800 & TGACCGAATGAGCAAGGAAATTACT & TACTCAGCTITGGCAATCCACATC \\
\hline$M d D F R$ & MD15G1024100 & AGGAACTGTGAATGTGGAGGAGC & AGGAACTGTGAATGTGGAGGAGC \\
\hline MdANS & MD06G1071600 & TCCCAAAAGAGTACATCAGACCTAA & ACACCCCAGTCCACAGTTGC \\
\hline$M d L A R$ & MD16G1048500 & TCTTGGCCCTACTITGACAAC & AGAGTTCCCACTTCCACATCA \\
\hline MdANR & MD10G1311100 & CCACCTCACAGCACTACAAGAG & GCAAATTTCCAAGCTGTCTTCT \\
\hline MdUFGT & MD01G1234400 & GCAAGCCGCAGGAGGACATA & CGGAGATCCAGAAAGTGACCCA \\
\hline MdLAC7 & MD04G1142300 & ATGGCACGGTTAGCCTTT & CTAACATTTCGGCAGATCAAGT \\
\hline MdLAC12 & MD01G1159400 & TGGAGGCACTCAACGCATTT & GATCTATAGATTCTTAACAA \\
\hline MdLAC14 & MD02G1264400 & ATGGCCTCAGACAAGAAAATAC & CTAAGACTTGGAACAAGGAGGCA \\
\hline MdLAC15 & MD07G1308000 & ATGAGTATTITAATTAGCTTGC & ACATGGAGGCATTCCTTGTGG \\
\hline MdLAC16 & MD07G1307400 & ATGCATCTCCACGGATTCAG & TGTTAACATGGAGGCATTCC \\
\hline
\end{tabular}

measured by Nitrogen-Blue Tetrazole photochemical reduction method. The CAT activity using the method of Kar and Mishra [45, 53]. The POD activity was determined by Guaiacol method.

\section{Total antioxidant capacity}

According to the methods of Lee and Wicker [54], $1.0 \mathrm{~g}$ peel was grounded in liquid nitrogen. Then, a $1.5 \mathrm{ml}$ alcohol-acetone mixture (v:v $=7: 3$ ) was added and incubated at $37^{\circ} \mathrm{C}$ for $1 \mathrm{~h}$. The homogenate was then centrifuged at $13,000 \mathrm{rpm}$ at $20^{\circ} \mathrm{C}$ for $10 \mathrm{~min}$. The supernatant was immediately stored in the $-20^{\circ} \mathrm{C}$ refrigerator, which used to determine the total antioxidant activity and content of antioxidant substances.

Total phenol content was spectrophotometrically determined according to the Folin-Ciocalteu method [55]. Flavonoids were determined by Nitrite-Aluminum Chloride [56], using rutin as standard, and the results were calculated using the rutin calibration curve. Flavanol content was detected with 4-DMACA [39]. The total antioxidant capacity of peel was determined by Iron reduction ability method.

\section{Phenolic acid composition}

According to the method described by Zhang [57] to measure the phenolic acid composition (with minor modifications). Briefly, $0.1 \mathrm{~g}$ fresh sample was weighed, and place it in a $1.5 \mathrm{~mL}$ centrifuge tube, then add $1.0 \mathrm{~mL}$ of extract (Methanol: Water: Formic acid $=25: 24: 1$; v:v: v), ultrasonic for $20 \mathrm{~min}$ at $25^{\circ} \mathrm{C}(40 \mathrm{~Hz}, 100 \mathrm{~W})$, then shocked for $20 \mathrm{~min}$, centrifuged $(10,000 \mathrm{rpm} 15 \mathrm{~min})$. After, the supernatant was absorbed with a syringe, it was filtered into a brown amber bottle with $0.25 \mu \mathrm{m}$ organic nylon filter, using Liquid Mass Spectrometry to determinate phenolic acid components. Mobile liquid A was $0.1 \%$ formic acid water, and mobile liquid $B$ was $100 \%$ methanol.

\section{Total RNA extraction and qPCR analysis}

Total RNA was extracted from the apple of peel (set up three independent replicates), using the RNA Plant Plus Reagent Kit (TIANGEN, China) and reverse transcribed into cDNA using PrimeScript ${ }^{\mathrm{rm}} \mathrm{RT}$ Reagent Kit (Takara, Dalian, China). Quantitative polymerase chain reactions (qPCRs) were carried out in the ABI7500 System using SYBR Premix Ex Taq (Takara). The calculation method for qRT-PCR was $2^{-\triangle \Delta C T}$. At least three replicates for each sample were used for qPCR. The primers used for $\mathrm{qPCR}$ are listed in Table 1.

\section{Statistical analysis}

Three biological repeats were taken from the experimental data. Microsoft Excel 2010, SigmaPlot 13, and Progenesis QI V2.3 software were used to process and plot the data, and SPSS 24.0 software was used to conduct a one-way analysis of variance (ANOVA). The data were analyzed using the t-test. The data were expressed as mean \pm standard error. Significance was defined at $p<0.05$.

\footnotetext{
Abbreviations

BFW: Bagging fruits without browning; BFB: Bagging fruits with browning; NBF: Non-bagging fruits; PLS-DA: Partial least squares discriminant analysis; VIP: Variable importance of projection; MDA: Malondialdehyde: $\mathrm{H}_{2} \mathrm{O}_{2}$ : Hydrogen peroxide; $\mathrm{O}_{2}^{-}$: Superoxide anion; FAO: Food and Agriculture Organization of the United Nations; TCA: Tricarboxylic acid cycle; GABA: $\gamma$ aminobutyric acid; QC: Quality control; PCA: Principal component analysis; KEGG: Kyoto encyclopedia of genes and genomes; ROS: Reactive oxygen species; SOD: Superoxide dismutase; CAT: Catalase from micrococcus lysodeiktic; POD: Peroxidase; TP: Total phenols; TFA: Total flavanols; TFO: Total flavonoids; PPO: Enzyme polyphenol oxidase; PAL: Phenylalanine ammonialyase; C4H: Cinnamate 4-hydroxylase; 4CL: 4-coumarate coenzyme A ligase; CHS: Chalone synthase; CHI: Chalcone isomerase; F3H: Flavanone 3hydroxylase; DFR: Dihydroflavonol reductase; ANS: Anthocyanidin synthase; LAR: Leucoanthocyanidin reductase; ANR: Anthocyanidin reductase; UFGT: UGP glucose-flavonoid3-o-glucosyl; LAC: P-diphenol dioxygen oxidoreductase; qRT-PCR: Quantitative real-time PCR; cDNA: Complementary DNA; 4-DMACA: 4-(Dimethylamino) cinnamaldehyde
} 


\section{Supplementary Information}

The online version contains supplementary material available at https://doi. org/10.1186/s12870-021-02974-y.

Additional file 1: Figure S1. Hierarchical clustering graph for screening different metabolites. A: BFW-NBF group; B: BFW-BFB group. Note: The abscissa represents the sample name, and the ordinate represents the differential metabolites. The color from green to red indicates the expression abundance of metabolites from low to high, that is, the redder indicates the expression abundance of different metabolites.

Additional file 2: Figure S2. The changing of temperature and humidity in the early stage of harvest. Note: The abscissa represents the date, the primary ordinate axis represents the daily highest temperature, the secondary ordinate axis represents the average relative humidity. AHtemp represents the daily highest temperature of NBF; BHtemp represents the daily highest temperature of $\mathrm{BF}$; Ahumi represents the average relative humidity of NBF; Bhumi represents the average relative humidity of BF.

Additional file 3: Table S1. Detailed metabolites of top 50 about BFWNBF group.

Additional file 4: Table S2. Detailed metabolites of top 50 about BFWBFB group

\section{Acknowledgements}

We appreciate the linguistic assistance provided by TopEdit (www.topeditsci.com) during the preparation of this manuscript. We thank the Shanghai LuMing biological technology Co., LTD (Shanghai, China) for providing metabolomics services.

\section{Authors' contributions}

ZYZ, HW and LLS conceived and designed the experiments. HW, SW, MMF and $\mathrm{SHZ}$ performed experiments. HW, SW and MMF contributed reagents, materials, and data analysis. ZYZ, HW and LLS wrote the paper. All authors have read and approved the manuscript.

\section{Funding}

This work was supported by the earmarked fund for the Special Project for Building Industrial Technology System of National Modern Agriculture (Apple) (CARS-28), the Modern Agro-industry Technology Research System, China (CARS-27); the Northwest A\&F University of Science and Technology (2014 YB 086), the Fundamental Research Funds for the Central Universities (2452020033). The funders did not play a role in the experimental design of the study, results analysis or writing of the manuscript, but did provide financial support for the manuscript.

\section{Availability of data and materials}

The raw metabonomics data have been deposited to the EMBL-EBI MetaboLights database with the identifier MTBLS2384. The complete dataset can be accessed here: https://www.ebi.ac.uk/metabolights/MTBLS2384/descriptors.

\section{Declarations}

Ethics approval and consent to participate

Not applicable.

\section{Consent for publication}

All authors agreed to publish.

\section{Competing interests}

The authors have no conflict of interest to declare.

\section{Author details}

${ }^{1}$ College of Horticulture, Northwest A \& F University, Yangling, Xianyang 712100, Shaanxi, China. ${ }^{2}$ College of Horticultural Science and Engineering, Shandong Agricultural University / State Key Laboratory of Crop Biology, Taian 271018, Shandong, China.
Received: 30 November 2020 Accepted: 14 April 2021

Published online: 08 May 2021

\section{References}

1. Zhao J, Quan PK, Liu HK, Li LL, Qi SY, Zhang MS, et al. Transcriptomic and metabolic analyses provide new insights into the apple fruit quality decline during long-term cold storage. J Agric Food Chem. 2020;68(16):4699-716. https://doi.org/10.1021/acs.jafc.9b07107.

2. Zhang XJ, Wang LX, Liu YL, Chen XX, Yang YZ, Zhao ZY. Differential geneexpression analysis of 'granny Smith' apple (Malus domestica Borkh.) during fruit skin coloration. S Afr J Bot. 2013;88(9):125-31. https://doi.org/1 0.1016/j.sajb.2013.07.009

3. Sharma RR, Pal RK, Sagar VR, Parmanick KK, Rana MR, Gupta VK, et al. Impact of pre-harvest fruit-bagging with different coloured bags on peel colour and the incidence of insect pests, disease and storage disorders in 'Royal Delicious' apple. J Hortic Sci Biotechnol. 2014;89(6):603-18.

4. Karara H, Ahmada M, Ullaha H, Wajidb M, Zubairb M, Razab H. Effectiveness of fruit bagging for the control of insect-pests complex and its impact on quality of mango fruits. J Hortic Sci Biotechnol. 2019;2(2):45-8.

5. Bentley WJ, Viveros M. Brown-bagging 'granny Smith' apples on trees stops codling moth damage. Calif Agric. 1992;46(4):30-2. https://doi.org/10.3733/ ca.v046n04p30.

6. Hofman PJ, Smith LG, Joyce DC, Johnson GL, Meiburg GF. Bagging of mango (Mangifera indica'Keitt') fruit influences fruit quality and mineral composition. Postharvest Biol Technol. 1997;12(1):83-91. https://doi.org/10.1 016/S0925-5214(97)00039-2.

7. Amarante $\mathrm{C}$, Banks NH, Max S. Effect of preharvest bagging on fruit quality and postharvest physiology of pears (Pyrus communis). N Z J Crop Hort Sci. 2002;30(2):99-107. https://doi.org/10.1080/01140671.2002.9514204.

8. Xu HX, Chen JW, Xie M. Effect of different light transmittance paper bags on fruit quality and antioxidant capacity in loquat. J Sci Food Agric. 2010; 90(11):1783-8

9. Tran DH, Yen $\mathrm{CR}$, Chen YKH. Effects of bagging on fruit characteristics and physical fruit protection in red pitaya (hylocereus spp.). Biol Agric Hortic. 2015:31(3):158-66. https://doi.org/10.1080/01448765.2014.991939.

10. Shlomo M. Efficiency of bagging pomegranate fruits. Acta Hortic. 2015; 1089(66):485-8

11. Chen CS, Zhang D, Wang YQ, Li PM, Ma FW. Effects of fruit bagging on the contents of phenolic compounds in the peel and flesh of 'Golden Delicious','Red Delicious', and 'Royal Gala' apples. Sci Hortic. 2012;142(7):6873. https://doi.org/10.1016/j.scienta.2012.05.001.

12. Wang L, Zhang $X$, Liu Y, Shi X, Wang Y, Zhang C, et al. The effect of fruit bagging on the color, phenolic compounds and expression of the anthocyaninbiosynthetic and regulatory genes on the 'granny Smith' apples. Eur Food Res Technol. 2013;237(6):875-85. https://doi.org/10.1007/ s00217-013-2055-1.

13. Feng F, Li M, Ma F, Cheng L. The effects of bagging and debagging onexternal fruit quality, metabolites, and the expression of anthocyaninbiosynthetic genes in 'Jonagold' apple (Malus domestica Borkh.). Sci Hortic. 2014;165(1):123-31. https://doi.org/10.1016/j.scienta.2013.11.008.

14. Pechous SW, Whitaker BD. Cloning and functional expression of an (E, E)alpha-farnesene synthase cDNA from peel tissue of apple fruit. Planta. 2004; 219(1):84-94. https://doi.org/10.1007/s00425-003-1191-4.

15. Zhao CR. Analysis of the unknown disease on 'Rui xue' apple fruit [D]. National Knowledge Infrastructure (CNKI): Northwest A\&F University; 2018. Abstract In English

16. Li J. Screening of special fruit-growing bags for new apple variety 'Ruixue' [D]. National Knowledge Infrastructure (CNKI): Northwest A\&F University; 2019. Abstract In English

17. Chen X, Wu QX, Chen ZSZ, Li TT, Zhang ZK, Gao HJ, et al. Changes in pericarp metabolite profiling of four litchi cultivars during browning. Food Res Int. 2019;120(6):339-51. https://doi.org/10.1016/j.foodres.2019.02.046.

18. Oak P, Deshpande A, Giri A, Gupta V. Metabolomic dynamics reveals oxidative stress in spongy tissue disorder during ripening of Mangifera indica L. fruit. Metabolites. 2019;9(11):255.

19. Luo H, Song J, Toivonen P, Gong YH, Forney C, Palmer LC, et al. Proteomic changes in 'ambrosia' apple fruit during cold storage and in response to delayed cooling treatment. Postharvest Biol Technol. 2018;137(11):66-76. https://doi.org/10.1016/j.postharvbio.2017.11.011.

20. Jordi GB, Busatto N, Christian L, Violeta LG, Costa F. Investigation of the transcriptomic and metabolic changes associated with superficial scald 
physiology impaired by lovastatin and 1-methylcyclopropene in pear fruit (cv. "blanquilla"). Hort Res. 2020;7:49.

21. Lim S, Lee JG, Lee EJ. Comparison of fruit quality and GC-MS-based metabolite profiling of kiwifruit 'Jecy green': natural and exogenous ethylene-induced ripening. Food Chem. 2017;234(11):81-92. https://doi. org/10.1016/j.foodchem.2017.04.163.

22. Liu DC, Zeng Q, Ji QX, Liu CF, Liu SB, Liu Y. A comparison of the ultrastructure and composition of fruits' cuticular wax from the wild-type 'newhall' navel orange (citrus sinensis osbeck cv. Newhall) and its glossy mutant. Plant Cell Rep. 2012;31(12):2239-46. https://doi.org/10.1007/s00299012-1333-x.

23. He YZ, Han JW, Liu RS, Ding YD, Wang JQ, Sun L, et al. Integrated transcriptomic and metabolomic analyses of a wax deficient citrus mutant exhibiting jasmonic acid-mediated defense against fungal pathogens. Hort Res. 2018;5(1):237-51.

24. Zhang LY, Hu J, Han XL, Li JJ, Gao Y, Richards C-M, et al. A high-quality apple genome assembly reveals the association of a retrotransposon and red fruit colour. Nat Commun. 2019;10(1):1494. https://doi.org/10.1038/s414 67-019-09518-X.

25. Sun $H D$, Gao Y, An XL, Jiang XL, Piao XC, Jin MY, et al. Optimization of the culture medium of adventitious root culture to produce the flavonoids and the triterpenoids of Actinidia arguta by using an orthogonal design process. Plant Cell Tiss Org. 2021;144(3):545-54. https://doi.org/10.1007/s11240-02001977-1.

26. Wang YC, Qu GZ, Li HY, Wu YJ, Wang C, Liu GF, et al. Enhanced salt tolerance of transgenic poplar plants expressing a manganese superoxide dismutase from Tamarix androssowii. Mol Biol Rep. 2009;37(2):1119-24.

27. Aebi H. Catalase. In: Bergmeyer HU, editor. Methods of enzymatic analysis. 2nd ed. New York: Academic Press; 1974. p. 673-84. https://doi.org/10.1016/ B978-0-12-091302-2.50032-3.

28. Pütter J. Peroxidases. In: Bergmeyer HU, editor. Methods of enzymatic analysis. 2nd ed. New York: Academic Press; 1974. p. 685-90. https://doi. org/10.1016/B978-0-12-091302-2.50033-5.

29. Wang XQ, Wei ZW, Ma FW. The effects of fruit bagging on levels of phenolic compounds and expression by anthocyanin biosynthetic and regulatory genes in red-fleshed apples. Process Biochem. 2015;50(11):1774982. https://doi.org/10.1016/j.procbio.2015.06.024.

30. Zhu H, Chen C, Zeng J, Yun Z, Liu YL, Qu HX, et al. MicroRNA528, a hub regulator modulating ROS homeostasis via targeting of a diverse set of genes encoding copper-containing proteins in monocots. New Phytol. 2019;225(1):385-99. https://doi.org/10.1111/nph.16130.

31. Nicola B, Brian F, Alice T, Urska V, Luca C, Franco B, et al. Target metabolite and gene transcription profiling during the development of superficial scald in apple (Malus x domestica Borkh). BMC Plant Biol. 2014;14(1):193.

32. Busatto N, Farneti B, Tadiello A, Vrhovsek U, Cappellin L, Biasioli F, et al. Apple fruit superficial scald resistance mediated by ethylene is associated with diverse metabolic processes. Plant J. 2018;93(2):270-85. https://doi. org/10.1111/tpj.13774.

33. Martins SIFS, Jongen WMF, Boekel MAJSV. A review of maillard reaction in food and implications to kinetic modelling. Trends Food Sci Technol. 2000; 11(9):364-73. https://doi.org/10.1016/S0924-2244(01)00022-X.

34. Wang $L$, Li JH, Gao JJ, Feng XX, Shi ZX, Gao FY, et al. Inhibitory effect of chlorogenic acid on fruit russeting in 'Golden delicious' apple. Sci Hortic. 2014;178(10):14-22. https://doi.org/10.1016/j.scienta.2014.07.038.

35. Tanaka Y, Sasaki N, Ohmiya A. Biosynthesis of plant pigments: anthocyanins, betalains and carotenoids. Plant J. 2008;54(4):733-49. https://doi.org/1 0.1111/j.1365-313X.2008.03447.X.

36. Lin $Y X$, Jiang $L Y$, Chen $Q$, Li YL, Zhang YT, Luo Y, et al. Comparative transcriptome profiling analysis of red- and white-fleshed strawberry (Fragaria $x$ ananassa) provides new insight into the regulation of the anthocyanin pathway. Plant Cell Physiol. 2018;59(9):1844-59. https://doi. org/10.1093/pcp/pcy098

37. Zhang XX, Zhang S, Yang YR, Wang D, Gao HY. Natural barrigenol-like triterpenoids: a comprehensive review of their contributions to medicinal chemistry. Phytochemistry. 2019;161(5):41-74. https://doi.org/10.1016/j. phytochem.2019.01.017.

38. Telias A, Bradeen JM, Luby JJ, Hoover EE, Allan AC. Regulation of anthocyanin accumulation in apple peel. Hortic Rev. 2011;38:357-91.

39. Fang YL, Meng JF, Zhang A, Liu JC, Xu TF, Yu WL, et al. Influence of shriveling on berry composition and antioxidant activity of cabernet sauvignon grapes from Shanxi vineyards. J Sci Food Agric. 2011;91(4):74957. https://doi.org/10.1002/jsfa.4246.

40. Gong YH, Song J, Du LN, Vinqvist M, Palmer LC, Fillmore S, et al. Characterization of laccase from apple fruit during postharvest storage and its response to diphenylamine and 1-methylcyclopropene treatments. Food Chem. 2018;253:314-21.

41. Pourcel L, Routaboul JM, Kerhoas L, Caboche M, Lepiniec L, Debeaujon I. TRANSPARENT TESTA10 encodes a laccase-like enzyme involved in oxidative polymerization of flavonoids in Arabidopsis seed coat. Plant Cell. 2005;17(11): 2966-80. https://doi.org/10.1105/tpc.105.035154.

42. Legay S, Guerriero G, Deleruelle A, Lateur M, Evers D, André CM, et al. Apple russeting as seen through the RNA-seq lens: strong alterations in the exocarp cell wall. Plant Mol Biol. 2015;88(1-2):21-40. https://doi.org/10.1007/ s11103-015-0303-4.

43. Zhao Q, Nakashima J, Chen F, Yin Y, Fu C, Yun J, et al. LACCASE is necessary and nonredundant with PEROXIDASE for lignin polymerization during vascular development in Arabidopsis. Plant Cell. 2013;25(10):3976-87. https://doi.org/10.1105/tpc.113.117770.

44. Lonegan G, Baker WL. Comparative study of substrates of fungal laccase. Lett Appl Microbiol. 1995;21(1):31-3. https://doi.org/10.1111/j.1472-765X.1 995.tb01000.x.

45. Walker JRL, Ferrar PH. Diphenol oxidases, enzymecatalysed browning and plant disease resistance. Biotechnol Genet Eng. 1998;15(1):457-98. https:// doi.org/10.1080/02648725.1998.10647966.

46. Boba A, Kostyn K, Kozak B, Wojtasik W, Kulma A. Fusarium oxysporum infection activates the plastidial branch of the terpenoid biosynthesis pathway in flax, leading to increased ABA synthesis. Planta. 2020;251(2):50. https://doi.org/10.1007/s00425-020-03339-9.

47. Gershenzon J, Dudareva N. The function of terpene natural products in the natural world. Nat Chem Biol. 2007;3(7):408-14. https://doi.org/10.1038/ nchembio.2007.5

48. Haralampidis K, Trojanowska M, Osbourn A-E. Biosynthesis of triterpenoid saponins in plants. Adv Biochem Eng Biotechnol. 2002;75(2):31-49. https:// doi.org/10.1007/3-540-44604-4_2.

49. Kubota T, Asaka Y, Miura I, Mori H. Structures of ganoderic acid a and b, two new lanostane type bitter triterpenes from ganoderma lucidum (fr.) karst. Helv Chim Acta. 1982;65(2):611-9. https://doi.org/10.1002/hlca.1982 0650221.

50. Ban QY, Han Y, Meng K, Hou YL, Rao JP. Characterization of $\beta$-Galactosidase genes involved in persimmon growth and fruit ripening and in response to propylene and 1-Methylcyclopropene. J Plant Growth Regul. 2016;35(4): 1025-35. https://doi.org/10.1007/s00344-016-9601-6.

51. Sun MX, Peng FT, Xiao YS, Yu W, Zhang YF, Gao HF. Exogenous phosphatidylcholine treatment alleviates drought stress and maintains the integrity of root cell membranes in peach. Sci Hortic-Amsterdam. 2020;259: 108821. https://doi.org/10.1016/j.scienta.2019.108821.

52. Zhao SJ, Shi GA, Dong XC. Experimental guidance of plant physiology, vol. 55-57. Beijing: China Agriculture Press; 2015. p. 142-3. (In Chinese)

53. De LA, Angelico R, Macciola V, Ceglie A. Effects of polyphenol enzymaticoxidation on the oxidative stability of virgin olive oil. Food Res Int. 2013; 54(2):2001-7.

54. Lee HS, Wicker L. Anthocyanin pigments in the skin of lychee fruit. J Food Sci. 1991;56(2):466-8. https://doi.org/10.1111/j.1365-2621.1991.tb05305.x.

55. Andriyani R, Budiati TA, Pudjiraharti S. Effect of extraction method on Total flavonoid, Total phenolic content, antioxidant and anti-bacterial activity of Zingiberis Officinale rhizome. Proc Chem. 2015;16:149-54. https://doi.org/1 0.1016/j.proche.2015.12.023.

56. Koyama K, Gotoyamamoto N. Bunch shading during different developmental stages affects the phenolic biosynthesis in berry skins of 'cabernet sauvignon' grapes. J Amer Soc Hort Sci. 2008;133(6):743-53. https://doi.org/10.21273/JASHS.133.6.743.

57. Zhang YZ, Li PM, Cheng LL. Developmental changes of carbohydrates, organic acids, amino acids, and phenolic compounds in 'Honeycrisp' apple flesh. Food Chem. 2020;123:1013-8.

\section{Publisher's Note}

Springer Nature remains neutral with regard to jurisdictional claims in published maps and institutional affiliations. 